\title{
Acute vasoreactivity test results in severe pulmonary hypertension patients with chronic obstructive pulmonary disease: our experience with 29 cases
}

\author{
This article was published in the following Dove Press journal: \\ International Journal of COPD \\ 28 May 2015 \\ Number of times this article has been viewed
}

\section{Selvi Asker \\ Muntecep Asker ${ }^{2}$ \\ 'Department of Chest Diseases, Van Yuksek Ihtisas Training and Research Hospital, Van, Turkey; ${ }^{2}$ Department of Cardiology, Van Yuksek Ihtisas Training and Research Hospital, Van, Turkey}

Aim: The aim of the current study is to evaluate acute vasoreactivity test (AVT) results in severe pulmonary hypertension patients with chronic obstructive pulmonary disease and to compare the demographical, clinical, and laboratory variables in positive and negative cases.

Methods: This retrospective, clinical study was performed on 29 cases in the departments of cardiology and chest diseases of our tertiary care center. AVT was positive in $12(41.4 \%)$ cases and negative in 17 (58.6\%) cases. Demographical variables, cardiopulmonary indicators, and laboratory findings were compared in these two subgroups.

Results: The mean age was $62.3 \pm 7.8$ years for AVT negative group, while it was $64.8 \pm 7.3$ years in AVT positive group ( $P=0.38)$. Except for the changes in systolic, diastolic, and mean pulmonary arterial pressures before and after iloprost administration, there were no statistically significant differences regarding any of the parameters under investigation in both groups.

Conclusion: Despite the high rate of positivity for AVT in severe pulmonary hypertension patients with chronic obstructive pulmonary disease, none of the variables under investigation displayed a noteworthy difference between AVT negative and positive groups. Identification of factors likely to influence AVT results is important for establishment of appropriate treatment protocols especially for AVT negative cases.

Keywords: chronic obstructive pulmonary disease, pulmonary hypertension, acute vasoreactivity test

\section{Introduction}

Positivity of acute vasoreactivity test (AVT) is "a fall of at least $10 \mathrm{mmHg}$ in mean pulmonary artery pressure (PAP); a fall to an absolute mean PAP less than $40 \mathrm{mmHg}$; and unchanged or increased cardiac output". ${ }^{1}$ AVT is typically performed with a short-acting agent such as inhaled nitric oxide, inhaled iloprost, intravenous epoprostenol, or adenosine. Baseline hemodynamic measurements are obtained prior to testing. ${ }^{1,2}$

AVT is performed for three reasons in pulmonary hypertension (PH): 1) identification of patients who may display a favorable long-term response to calcium channel blocker treatment, 2) gathering prognostic information, 3) scientific research purposes. $^{2-4}$ In $\mathrm{PH}$ patients with COPD, AVT usually yields positive results. The response rate in an adult population is reported to vary between $13 \%$ and $35 \%$ in different series. These cases not only display better functional class and hemodynamics, but they also have superior survival rates compared to non-responders. . $^{1,3,4}$
Correspondence: Selvi Asker

Department of Chest Diseases, Yuzuncu Yil University Faculty of Medicine, 65I70,

Van, Turkey

Tel +90505 25I 4704

$\mathrm{Fax}+904322121954$

Email selviasker@yahoo.com 
Positivity of AVT is not routinely expected for all COPD patients. Documentation of AVT results in COPD patients with severe $\mathrm{PH}$ and recognition of characteristics of patients with respect to AVT results may yield useful clues for setting convenient treatment regimens.

The aim of the current study is to evaluate AVT results in severe PH patients with COPD and to compare the demographic, clinical, and laboratory variables in vasoreactivity test positive and negative cases. Thereby, better understanding of the underlying pathophysiological mechanisms and setting potential new treatment modalities may be possible.

\section{Material and methods Study design}

This study was approved by the local Institutional Review Board (September 18, 2013) and written informed consent was obtained from all participants. The procedures followed were in accordance with the Helsinki Declaration of 1975, as revised in 2000 (concerning the ethical principles for the medical community and forbidding releasing the name of the patient, initials or the hospital evidence number) and with the ethical standards of the responsible committee on human experimentation (institutional and national).

A total of 29 severe $\mathrm{PH}$ patients with stable COPD, who were under follow-up in the departments of cardiology and chest diseases of our tertiary care center, were included in this study. All patients had been diagnosed with PH secondary to COPD and they suffered from dyspnea after minimal or moderate exertion. However, they were clinically stable and had been free from bronchopulmonary infection, acute respiratory distress, or right ventricular failure for at least 3 months prior to the study. All patients were devoid of any clinical, electrocardiographic, X-ray or echographic findings consistent with left ventricular dysfunction. Patients with interstitial lung diseases and obstructive sleep apnea were excluded from the study.

Outcome parameters: AVT was performed using inhalation of $1 \mathrm{~mL}$ of iloprost trometamol (Ilomedin ${ }^{\circledR} 20 \mathrm{mcg} / \mathrm{mL}$; Schering AG, Berlin-Wedding, Germany) as described by Opitz et al. ${ }^{3}$ Testing at the time of catheterization with a short-acting pulmonary vasodilator is critical in determining the therapeutic options for patients with pulmonary arterial hypertension. A positive acute vasoreactive response is defined as a reduction of mean PAP $\geq 10 \mathrm{mmHg}$ to reach an absolute value of mean PAP $\leq 40 \mathrm{mmHg}$ with an increased or unchanged cardiac output..$^{5} \mathrm{PH}$ was described as mean PAP $>25 \mathrm{mmHg} .{ }^{4}$

Demographical features (age, sex, body mass index, smoking habit, history of exposure to biomass, systemic diseases such as diabetes mellitus, hypertension, coronary artery disease), as well as cardiopulmonary indicators (ejection fraction, forced expiratory volume in 1 second, forced vital capacity, systolic, diastolic, and mean PAP values before and after vasoreactivity test, oxygen saturation, partial pressures of $\mathrm{O}_{2}$ [oxygen] and $\mathrm{CO}_{2}$, [carbon dioxide], blood $\mathrm{pH}$ and $\mathrm{HCO}_{3}$ [bicarbonate] concentration) were noted. These variables are compared in AVT positive and negative patients.

\section{Statistical analyses}

Data were analyzed using the IBM Statistical Package for Social Sciences version 21 (IBM Corporation, Armonk, NY, USA). A normal distribution of the univariate data was checked using Kolmogorov-Smirnov test and ShapiroWilk test. A normal distribution of the multivariate data was checked using Mardia, Doornik and Omnibus tests. Comparison of two independent groups was performed with independent samples $t$-test and Mann-Whitney $U$-test. Dependent groups were compared via Wilcoxon signed rank test with simulation technique. The distribution of categorical variables in both groups was compared using Pearson's chi-squared test with Monte Carlo simulation technique, and Fisher's exact tests. A univariate analysis of potential risk factors was performed with the log-rank test for categorical factors and with the univariate Cox analysis for continuous variables. The cut-off points were calculated by the MedCalc software as the points with the best sensitivity-specificity balance. Quantitative variables were expressed as either mean \pm standard deviation or median-interquartile range. Confidence interval was set at $95 \%$ and a statistical difference was taken as $P<0.05$.

\section{Results}

The mean age and the body mass index for the whole study population was $63.4 \pm 7.5$ (range, 45 to 78 ) years and $27.3 \pm 5.7$ (range, 18 to 40$) \mathrm{kg} / \mathrm{m}^{2}$, respectively. The demographical, clinical, and laboratory features of the total $29 \mathrm{PH}$ patients are outlined in Table 1. Of the total 29 cases, 12 (41.4\%) had yielded positive AVT, while 17 (58.6\%) had negative AVT results. No complications or side effects were observed after AVT. There was no difference between AVT negative and positive patients with respect to incidences of comorbidities such as diabetes mellitus, hypertension, coronary artery disease, and smoking habit.

Table 2 demonstrates a comparative presentation of all variables under investigation for AVT negative $(n=17$, $58.6 \%)$ and positive $(n=12,41.4 \%)$ patients. As it can be 
Table I Demographical, clinical, and laboratory variables in the whole study group

\begin{tabular}{|c|c|}
\hline Variable & \\
\hline Age (years) & $63.4 \pm 7.5(45-78)$ \\
\hline \multicolumn{2}{|l|}{ Sex } \\
\hline Female (n, \%) & 17 (58.6\%) \\
\hline Male (n, \%) & $12(4 \mid .4 \%)$ \\
\hline Body mass index $\left(\mathrm{kg} / \mathrm{m}^{2}\right)$ & $27.3 \pm 5.7(18-40)$ \\
\hline \multicolumn{2}{|l|}{ Smoking habit } \\
\hline Yes (n, \%) & $16(55.2 \%)$ \\
\hline No (n, \%) & I3 (44.8\%) \\
\hline \multicolumn{2}{|l|}{ Biomass exposure } \\
\hline Yes (n, \%) & $17(58.6 \%)$ \\
\hline No (n, \%) & $12(4 \mid .4 \%)$ \\
\hline \multicolumn{2}{|l|}{ Coronary artery disease } \\
\hline Yes (n, \%) & $9(31 \%)$ \\
\hline No (n, \%) & $20(69 \%)$ \\
\hline \multicolumn{2}{|l|}{ Vasoreactivity test } \\
\hline Positive (n, \%) & $12(4 \mid .4 \%)$ \\
\hline Negative (n, \%) & $17(58.6 \%)$ \\
\hline Ejection fraction $(\%)^{\ddagger}$ & $57.5 \pm 4.2(50-68)$ \\
\hline $\mathrm{FEV}_{1}(\mathrm{~L})^{\ddagger}$ & $40.5 \pm 14.3(14-86)$ \\
\hline $\mathrm{FEV}_{\mathrm{l}} / \mathrm{FVC}^{\ddagger}$ & $64.0 \pm 3.8(52-68)$ \\
\hline $\mathrm{FVC}(\mathrm{L})^{\ddagger}$ & $49.0 \pm 15.8(27-85)$ \\
\hline Systolic PAP $(\mathrm{mmHg})^{\#}$ & $65.0 \pm 13.6(33-90)$ \\
\hline Duration of COPD (years) ${ }^{\#}$ & $8.0 \pm 4.3(3-20)$ \\
\hline Oxygen saturation (\%) ${ }^{\#}$ & $77.2 \pm 10.7(58-93)$ \\
\hline $\mathrm{PO}_{2}(\mathrm{mmHg})^{\#}$ & $46.1 \pm 10.8(20-66)$ \\
\hline $\mathrm{PCO}_{2}(\mathrm{mmHg})^{\#}$ & $49.3 \pm 8.3(33-68)$ \\
\hline $\mathrm{pH}^{\ddagger}$ & $7.38 \pm 0.02(7.35-7.44)$ \\
\hline $\mathrm{HCO}_{3}$ concentration $(\mathrm{mmol} / \mathrm{L})^{\#}$ & $27.4 \pm 3.4(23-35)$ \\
\hline
\end{tabular}

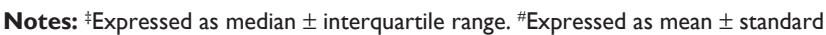
deviation.

Abbreviations: FEV, forced expiratory volume in I second; FVC, forced vital capacity; $\mathrm{PO}_{2}$, oxygen pressure; $\mathrm{PCO}_{2}$, carbon dioxide pressure; $\mathrm{HCO}_{3}$, bicarbonate; PAP, pulmonary artery pressure.

seen, there was no difference in AVT negative and positive patients in terms of any parameters.

The systolic, diastolic, and mean PAPs before and after administration of iloprost are shown in Table 3. Change in systolic PAP before and after iloprost is $3.0 \pm 4.0 \mathrm{mmHg}$ in AVT negative group and $13.5 \pm 6.5 \mathrm{mmHg}$ in AVT positive group $(P<0.001)$. Change in diastolic PAP before and after iloprost is $1.0 \pm 4.0 \mathrm{mmHg}$ in AVT negative group and $9.5 \pm 9.0 \mathrm{mmHg}$ in AVT positive group $(P<0.001)$. Change in mean PAP before and after iloprost is $2.0 \pm 2.0 \mathrm{mmHg}$ in AVT negative group and $11.0 \pm 8.0 \mathrm{mmHg}$ in AVT positive group $(P<0.001)$.

Comparison of changes in systolic, diastolic, and mean PAPs after iloprost administration in AVT negative and positive patients can be seen in Table 4 . Even though all three PAPs are significantly altered $(P<0.001$ for each), the change in systolic PAP appears to be more prominent between AVT positive and negative patients.
Table 2 Comparison of parameters under investigation in patients with positive and negative vasoreactivity test results

\begin{tabular}{|c|c|c|c|}
\hline \multirow[t]{2}{*}{ Variable } & \multicolumn{2}{|c|}{ Vasoreactivity test } & \multirow[t]{2}{*}{$P$-value } \\
\hline & Negative & Positive & \\
\hline Age (years) & $62.3 \pm 7.8$ & $64.8 \pm 7.3$ & 0.38 \\
\hline \multicolumn{4}{|l|}{ Hypertension } \\
\hline Absent (n, \%) & $13(76.5 \%)$ & 9 (75\%) & I \\
\hline Present (n, \%) & $4(23.5 \%)$ & $3(25 \%)$ & \\
\hline \multicolumn{4}{|l|}{ Coronary artery disease } \\
\hline Absent (n, \%) & $12(70.6 \%)$ & $8(66.7 \%)$ & I \\
\hline Present (n, \%) & $5(29.4 \%)$ & $4(33.3 \%)$ & \\
\hline \multicolumn{4}{|l|}{ Biomass exposure } \\
\hline Absent (n, \%) & 7 (4I.2\%) & $5(4 \mid .7 \%)$ & I \\
\hline Present (n, \%) & $10(58.8 \%)$ & 7 (58.3\%) & \\
\hline \multicolumn{4}{|l|}{ Diabetes mellitus } \\
\hline Absent (n, \%) & II (64.7\%) & $10(83.3 \%)$ & $0.4 I$ \\
\hline Present (n, \%) & $6(35.3 \%)$ & $2(16.7 \%)$ & \\
\hline \multicolumn{4}{|l|}{ Smoking habit } \\
\hline Absent (n, \%) & $8(47.1 \%)$ & $5(4 \mid .7 \%)$ & I \\
\hline Present $(n, \%)$ & $9(52.9 \%)$ & $7(58.3 \%)$ & \\
\hline Body mass index $\left(\mathrm{kg} / \mathrm{m}^{2}\right)$ & $27.5 \pm 6.1$ & $27.1 \pm 5.3$ & 0.86 \\
\hline Ejection fraction $(\%)^{\ddagger}$ & $56.0 \pm 5.0$ & $60.0 \pm 5.0$ & 0.52 \\
\hline $\mathrm{FEV}_{1}(\mathrm{~L})^{\ddagger}$ & $40.0 \pm 12.0$ & $39.0 \pm 20.0$ & 0.85 \\
\hline $\mathrm{FEV}_{\mathrm{l}} / \mathrm{FVC}^{\ddagger}$ & $64.0 \pm 3.0$ & $64.50 \pm 4.0$ & 0.82 \\
\hline FVC $\%^{\ddagger}$ & $48.0 \pm 11.0$ & $45.0 \pm 30.5$ & 0.51 \\
\hline Systolic PAP (mmHg)\# & $65.8 \pm 12.4$ & $63.8 \pm 15.7$ & 0.71 \\
\hline Duration of COPD (years) $)^{\ddagger}$ & $8.0 \pm 4.0$ & $6.0 \pm 4.5$ & 0.39 \\
\hline Oxygen saturation (\%) & $76.5 \pm 9.9$ & $78.2 \pm 11.9$ & 0.89 \\
\hline $\mathrm{PO}_{2}(\mathrm{mmHg})^{\#}$ & $47.0 \pm 9.0$ & $44.8 \pm 13.1$ & 0.60 \\
\hline $\mathrm{PCO}_{2}(\mathrm{mmHg})^{\#}$ & $51.2 \pm 7.7$ & $46.8 \pm 8.7$ & 0.16 \\
\hline $\mathrm{pH}^{\ddagger}$ & $7.38 \pm 0.02$ & $7.39 \pm 0.04$ & 0.46 \\
\hline $\mathrm{HCO}_{3}(\mathrm{mmol} / \mathrm{L})^{\#}$ & $27.9 \pm 3.6$ & $26.8 \pm 3.1$ & 0.36 \\
\hline
\end{tabular}

Notes: 故pressed as median \pm interquartile range. "Expressed as mean \pm standard deviation.

Abbreviations: $\mathrm{FEV}_{1}$, forced expiratory volume in I second; FVC, forced vital capacity; $\mathrm{PO}_{2}$, oxygen pressure; $\mathrm{PCO}_{2}$, carbon dioxide pressure; $\mathrm{HCO}_{3}$, bicarbonate; PAP, pulmonary artery pressure.

\section{Discussion}

In this study, we attempted to demonstrate whether there was a difference between AVT negative and positive $\mathrm{PH}$ patients in terms of demographical, clinical, and cardiopulmonary variables. Our study has shown that only systolic, diastolic, and mean PAPs exhibited a significant difference before and after administration of iloprost for AVT between the two groups.

Assessment of AVT helps to estimate the overall prognosis and to identify patients who may be calcium channel blocker treatment responders. There is a disproportionate rate of $\mathrm{PH}$ in COPD patients. The reported rate of $\mathrm{PH}$ in COPD is about $35 \%-40 \%$. $^{6}$ If left ventricular functions are normal, diseases other than COPD should be excluded. Even if the exact cause cannot be identified, attributed to the likelihood of vascular changes similar to advanced COPD cases, we suggest that vasodilator drugs mentioned above can be beneficial for this 
Table 3 Alterations of systolic, diastolic, and mean pulmonary arterial pressures before and after iloprost administration

\begin{tabular}{lll}
\hline Parameter (mmHg) & Vasoreactivity test & Positive \\
\cline { 2 - 3 } & Negative & $68.5 \pm 20.5$ \\
\hline Systolic PAP prior to iloprost & $69 \pm 22$ & $51 \pm 19$ \\
Systolic PAP after iloprost & $66 \pm 23$ & $13.5 \pm 6.5$ \\
Change in systolic PAP before and after iloprost & $3 \pm 4$ & $29.5 \pm 10.5$ \\
Diastolic PAP prior to iloprost & $28 \pm 15$ & $20 \pm 6$ \\
Diastolic PAP after iloprost & $28 \pm 16$ & $9.5 \pm 9$ \\
Change in diastolic PAP before and after iloprost & $1 \pm 4$ & $40 \pm 11.5$ \\
Mean PAP prior to iloprost & $40 \pm 17$ & $26.5 \pm 8.5$ \\
Mean PAP after iloprost & $36 \pm 18$ & $11 \pm 8$ \\
Change in mean PAP before and after iloprost & $2 \pm 2$ & $<0.001 *$ \\
\hline
\end{tabular}

Notes: Data is expressed as median \pm interquartile range. *Statistically significant $(P<0.05)$.

Abbreviation: PAP, pulmonary artery pressure.

subgroup. Acute vasoreactivity is observed in less than $20 \%$ of patients with idiopathic $\mathrm{PH}$ and these cases display better functional class and hemodynamic profile and have superior survival rates compared with non-responders even under treatment with other agents. ${ }^{1-4}$ Most of responders to AVT will have idiopathic $\mathrm{PH}$ or familial $\mathrm{PH}$ and some $\mathrm{PH}$ experts advocate that such testing be done in all patients receiving a new diagnosis of idiopathic or familial $\mathrm{PH}^{2,3}$

Regardless of the medication used for AVT, factors that can have a transient effect on pressure values should be eliminated. Such factors include acidosis, systemic arterial hypotension or hypertension, changes in temperature, arrhythmias, pulmonary ventilation asymmetry, and variations in the level of sedation during the measurements., 3 The interpretation of the results of tests used to determine pulmonary vasoreactivity in cases of idiopathic $\mathrm{PH}$ or in $\mathrm{PH}$ associated with systemic diseases should focus on changes in pulmonary and systemic pressures. However, in cases of congenital heart disease, alterations in resistances and in pulmonary and systemic outputs must be taken into account.
In cases of heart disease, there can be significant output changes, with resistance alterations, but without significant pressure changes. ${ }^{4,7,8}$

AVT may be a valuable measure in the investigative arena. This is especially true as we tried to elucidate demographical, clinical, and laboratory parameters, which may be associated with negativity/positivity of AVT. Results of tests used to determine pulmonary vasoreactivity can be affected by various transient changes that should be recognized and corrected.

Our results have shown that neither demographical variables, age, body mass index, sex, and systemic diseases (such as diabetes mellitus, hypertension, coronary artery disease) nor cardiopulmonary indicators seem to have an impact on the response to AVT. Biomass exposure, which is an important part of local lifestyle in rural areas, was investigated but no difference was detected between the two groups. We suggest that identification of demographic, clinical, and laboratory correlates of AVT positivity calls for utilization of more sophisticated measures on larger

Table 4 Changes in systolic, diastolic, and mean pulmonary artery pressures (PAP) after iloprost administration in vasoreactivity test negative and positive patients

\begin{tabular}{lll}
\hline Parameter $(\mathbf{m m H g})$ & Vasoreactivity test & P-value \\
\cline { 2 - 3 } & Negative $(\mathbf{n}, \%)$ & Positive $(\mathbf{n}, \%)$ \\
\hline $\begin{array}{l}\text { Change in systolic PAP } \\
\quad<6\end{array}$ & $17(100 \%)$ & 0 \\
$\quad \geq 6$ & 0 & $12(100 \%)$ \\
$\begin{array}{l}\text { Change in diastolic PAP } \\
\quad<.5\end{array}$ & $15(88.2 \%)$ & $3(25 \%)$ \\
$\geq 4.5$ & $2(11.8 \%)$ & $9(75 \%)$ \\
$\begin{array}{l}\text { Change in mean PAP } \\
<6.5\end{array}$ & $16(94.1 \%)$ & $3(25 \%)$ \\
$\geq 6.5$ & $1(5.9 \%)$ & $9(75 \%)$ \\
\hline
\end{tabular}

Note: * Statistically significant $(P<0.05)$. 
samples. We observed that the change in systolic PAP was more noteworthy than diastolic or mean PAP. This point can be important for planning further studies since parameters influencing systolic PAP may have a more obvious effect on the response to AVT.

Hemodynamic signs of right heart failure and subsequent PH may exist in some COPD cases. ${ }^{7-9}$ Chronic hypoxic vasoconstriction plays a crucial role in pathogenesis of PH. ${ }^{10-12}$ Since vasoreactivity test is negative in the majority of our patients, we speculate that a direct causal relationship between COPD and all PH cases is rather unlikely. Other pathophysiological processes which may contribute to development of PH must be studied while taking further diagnostic and therapeutic steps in these diseases. Distinguishing cases who respond positively to AVT may aid in selection of patients for whom COPD is more likely to be responsible in the etiopathogenesis of $\mathrm{PH}$.

Some limitations of this study must be noted: first, our sample size is small and the study design is retrospective. Second, impacts of any other metabolic, inflammatory or local factors which could influence AVT results could not be completely eliminated. Chance sampling is another factor prone to affect the distribution rate of responders to vasoreactivity test. Therefore, interpretations must be made with caution.

\section{Conclusion}

In conclusion, we came across a high rate of positivity for AVT in severe PH patients with COPD. However, none of the variables under investigation displayed a noteworthy difference between AVT negative and positive groups. Identification of factors likely to influence AVT results is important for establishment of appropriate treatment protocols for especially AVT negative cases.

\section{Disclosure}

The authors declare no conflicts of interest. No financial support was received for this paper.

\section{References}

1. Saadjian AY, Philip-Jöel FF, Barret A, Levy S, Arnaud AG. Effect of almitrine bismesylate on pulmonary vasoreactivity to hypoxia in chronic obstructive pulmonary disease. Eur Respir J. 1994;7(5):862-868.

2. Robbins IM, Barst RJ, Channick RN, Rubin LJ. Pulmonary vasoreactivity in PPH. J Am Coll Cardiol. 2001;38(4):1267-1268.

3. Opitz CF, Wensel R, Bettmann M, et al. Assessment of the vasodilator response in primary pulmonary hypertension: comparing prostacyclin and iloprost administered by either infusion or inhalation. Eur Heart J. 2003;24(4):356-365.

4. Oliveira EC, Amaral CF, Moura MA, Campos FT, Pauperio HM. Testing pulmonary vasoreactivity. J Bras Pneumol. 2008;34(10):838-844.

5. Barst RJ, McGoon M, Torbicki A, et al. Diagnosis and differential assessment of pulmonary arterial hypertension. J Am Coll Cardiol. 2004; 43(12 Suppl S):40S-47S.

6. Galiè N, Hoeper MM, Humbert M, et al. ESC Committee for Practice Guidelines (CPG). Guidelines for the diagnosis and treatment of pulmonary hypertension: the Task Force for the Diagnosis and Treatment of Pulmonary Hypertension of the European Society of Cardiology (ESC) and the European Respiratory Society (ERS), endorsed by the International Society of Heart and Lung Transplantation (ISHLT). Eur Heart J. 2009;30(20):2493-2537.

7. Weitzenblum E, Apprill M, Oswald M, Chaouat A, Imbs JL. Pulmonary hemodynamics in patients with chronic obstructive pulmonary disease before and during an episode of peripheral edema. Chest. 1994;105(5): 1377-1382.

8. Saadjian A, Philip-Joët F, Barret A, Levy S, Arnaud A. Nifedipine inhibits the effects of almitrine in patients suffering from pulmonary artery hypertension secondary to chronic obstructive pulmonary disease. J Cardiovasc Pharmacol. 1993;21(5):797-803.

9. Coccagna G, Lugaresi E. Arterial blood gases and pulmonary and systemic arterial pressure during sleep in chronic obstructive pulmonary disease. Sleep. 1978;1(2):117-124.

10. Fletcher EC, Levin DC. Cardiopulmonary hemodynamics during sleep in subjects with chronic obstructive pulmonary disease: the effect of short- and long term oxygen. Chest. 1984;85(1):6-14.

11. Adnot S, Andrivet P, Chabrier PE, et al. Atrial natriuretic factor in chronic obstructive lung disease with pulmonary hypertension. Physiological correlates and response to peptide infusion. J Clin Invest. 1989; 83(3):986-993.

12. Laks L, Lehrhaft B, Grunstein RR, Sullivan CE. Pulmonary hypertension in obstructive sleep apnoea. Eur Respir J. 1995;8(4):537-541.
International Journal of COPD

\section{Publish your work in this journal}

The International Journal of COPD is an international, peer-reviewed journal of therapeutics and pharmacology focusing on concise rapid reporting of clinical studies and reviews in COPD. Special focus is given to the pathophysiological processes underlying the disease, intervention programs, patient focused education, and self management protocols.

\section{Dovepress}

This journal is indexed on PubMed Central, MedLine and CAS. The manuscript management system is completely online and includes a very quick and fair peer-review system, which is all easy to use. Visit $\mathrm{http}: / / \mathrm{www}$. dovepress.com/testimonials.php to read real quotes from published authors. 